\title{
Study of sociodemographic factors of women undergoing caesarean section in tertiary care centre of rural area of central India
}

\author{
Shuchi M. Jain ${ }^{1 *}$, Ketki Thool ${ }^{1}$, Poonam V. Shivkumar ${ }^{1}$, Manish A. Jain ${ }^{2}$
}

\begin{abstract}
${ }^{1}$ Department of Obstetrics and Gynecology, Mahatma Gandhi Institute of Medical Sciences, Sevagram, Maharashtra, India

${ }^{2}$ Department of Paedriatrics, Mahatma Gandhi Institute of Medical Sciences Sevagram, Wardha, Maharashtra, India
\end{abstract}

Received: 17 September 2019

Accepted: 25 October 2019

\author{
*Correspondence: \\ Dr. Shuchi M. Jain, \\ E-mail: shuchimjain@gmail.com
}

Copyright: () the author(s), publisher and licensee Medip Academy. This is an open-access article distributed under the terms of the Creative Commons Attribution Non-Commercial License, which permits unrestricted non-commercial use, distribution, and reproduction in any medium, provided the original work is properly cited.

\begin{abstract}
Background: Many studies have attempted to examine and evaluate the changes in population characteristics that may have contributed to the observed increase in CS rate. The aim of this study was to determine the caesarean section rate and demographic characteristics of women undergoing caesarean section in our rural tertiary health centre of central India.

Methods: This prospective study was conducted in department of obstetrics and gynecology. The study instrument comprised a pre-structured data collection proforma which had various sections; social demographic characteristics, obstetric history and gestation details.

Results: The overall caesarean section rate (CSR) was 36.88\%. Maximum women (39.62\%) who underwent Caesarean section were of age group 25-29 years. 58.05\% from rural while $41.95 \%$ from urban area. CS was more in women of lower middle $(22.80 \%)$ and upper lower $(20.80 \%)$ class. Majority of women who had caesarean section were educated till higher school $(31.87 \%)$ or were graduate $(22.61 \%), 5.85 \%$ were illiterate. Majority of women $(56.40 \%)$ were housewives. CSR was $70.83 \%$ in referred and $28.31 \%$ in booked. $52.86 \%$ women were nulliparous. Caesarean section was maximum $(83 \%)$ in term, $16.92 \%$ preterm women and $0.08 \%$ post term women. $38.69 \%$ were referred from other health facilities. Maximum referrals $43.21 \%$ were from the district hospital.

Conclusions: It was noted that the preference for caesarean section is more in women of 25-29 years, lower middle and upper middle class, rural women, educated upto high school and housewives at our centre. This hospital also serves as referral centre from surrounding health facilities increasing the caesarean section rate of the institute.
\end{abstract}

Keywords: Caesarean section, Central India, Rural area, Socio-demographic factors

\section{INTRODUCTION}

Caesarean section (CS) was brought in clinical practice as a lifesaving procedure both for mother and baby. CS is a surgical intervention which is carried out to assure safety of mother and child when vaginal delivery is difficult or when the doctors consider that the danger to the mother and baby would be greater with a vaginal delivery. One of the important indicators of emergency obstetric care is CS rate (World Health Organization 2009).

A woman's socioeconomic characteristics have been reported to be associated with her risk of CS, although the direction of the association has not been unambiguous. The rapid rise of $\mathrm{CS}$ rate all around the world has become a grievous public health issue. It is 
because several studies have showed that increased rate of caesarean section does not necessarily contribute to an improved and better maternal health and pregnancy outcome. WHO global survey on maternal and perinatal health in Latin America, in fact, unveiled that rate of caesarean delivery was positively associated with severe maternal and neonatal morbidity and mortality ,even after adjustment of demographic characteristics, risk factors, type of institution and proportion of referrals. ${ }^{1}$ Also, unneeded caesareans beget higher expenditure at individual and national levels and have the potential to divert human and financial resources. In spite of these facts, CS is high and continues to hike in the developed world and in many developing countries. ${ }^{2}$

After knowing incidence of CS it is very clear that CSRs are increasing globally. The rising trend in c-section rates, in both developed as well as developing countries, and the higher preference given to this mode of delivery, points to the growing medicalisation of women's health. CS delivery is an example of the medicalisation of the human body.

Rising rate of CS is an important issue, attempts for demedicalisation of CS and thereby reducing CS is needed. Knowledge of CS determinants is a first step in the effort to reduce unnecessary and fruitless CSs. Thus, it is important to identify what combinations of demographic, clinical, and organizational variables best predict which women have a higher risk of CS. The determinants of CS are very complex and include not only clinical indications, but also economic and organizational factors, the physicians' attitudes toward birth management, and the social and cultural attitudes of women. Most clinical indications are not absolute and many are very subjective and culture-bound, so there is significant variability among hospitals and countries with respect to CS rates for particular medical indications. ${ }^{3}$ The aim of our study was to determine the CS rate and demographic characteristics of women undergoing $\mathrm{CS}$ in our rural tertiary health care centre.

\section{METHODS}

This prospective study was conducted in department of obstetrics and gynecology, in a rural tertiary care institute located in central India over a period of 18 months from July 2016 to December 2017. This institute is a rural medical college catering to the health care needs of the surrounding population in Wardha district of Maharashtra state of India. It also receives referrals from nearby districts. It is the first model maternal and child health wing of India. It is a nonprofitable organization. This study was aimed to describe the prominent and mostly frequent sociodemographic characteristics of mother's who had their caesarean delivery. The descriptive and quantitative data were collected based on the aim of the study.

Women included in our study were all women who underwent CS over a period of 18 months from July 2016 to December 2017 in our hospital. The study was conducted using a pre-structured data collection tool which had various sections; social demographic characteristics, obstetric history and gestation details. Pre-testing of the data collection tool was done to determine suitability. They were studied in detail with regards to socio demographic characteristics of womenlike age, education, occupation, socioeconomic status, rural or urban residence etc. Obstetrics history was taken in details regarding her gravidity, parity, abortion and living children status. Gestational weeks were noted and thereby preterm term and postdated patients were noted. Referral status and mode of admission i.e. Routine hours or emergency hours was noted. Data was collected by face to face interview. Data was entered in MS excel sheet and analyzed with percentage and chi square test using SPSS ver.17.

Clearance and approval from Institutional ethical and Research committee was obtained. Written informed consent was obtained from each woman. Privacy and anonymity were maintained throughout the study.

\section{RESULTS}

During audit period of eighteen months there were a total of 6908 deliveries, out of which 2548 were LSCS and 4360 were vaginal deliveries so the CS rate (CSR) in our rural tertiary health care centre was $36.88 \%$ (Figure 1).

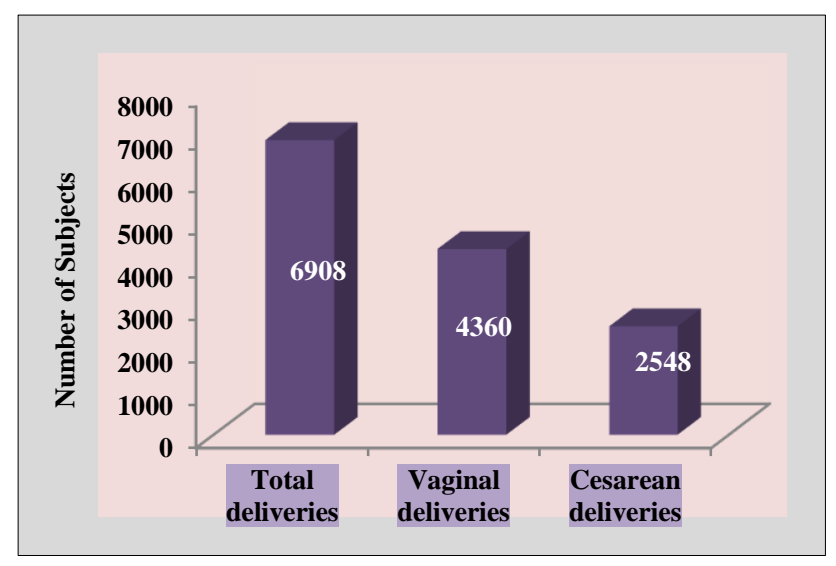

Figure 1: Caesarean section rate in tertiary health care centre $(36.88 \%)$.

All the 2548 women who underwent LSCS were studied for sociodemographic characteristics maximum women (39.62\%) who underwent CS were of age group 25-29 years. Only $1.5 \%$ women were below 20 years. Maximum age was 41 years and minimum were 18 years. Out total CS $58.05 \%$ were from rural area while $41.95 \%$ were from urban area. CS was more in women of lower middle $(22.80 \%)$ and upper lower $(20.80 \%)$ class. In most of the emergency sections women were of upper lower class while or lower middle class, however, most of the women in elective sections were of upper middle class. Majority of women who had CS were educated till 
higher school $(31.87 \%)$ or were graduate $(22.61 \%)$. $5.85 \%$ were illiterate. Majority of women $(56.40 \%)$ who underwent Caesarean section were housewives (Table 1).

Table 1: Socio demographic characteristics of women undergoing caeserean section.

\begin{tabular}{|c|c|c|}
\hline Women & Total (2548) & Percentage \\
\hline \multicolumn{3}{|l|}{ Age (years) } \\
\hline Up to 20 years & 61 & 2.4 \\
\hline 21-24 years & 814 & 31.9 \\
\hline $25-29$ years & 1150 & 45.1 \\
\hline 30-34 years & 395 & 15.5 \\
\hline$>34$ years & 128 & 5.0 \\
\hline \multicolumn{3}{|l|}{ Place of residence } \\
\hline Urban $(n=1054)$ & 1069 & 41.95 \\
\hline Rural (n=1484) & 1479 & 58.05 \\
\hline \multicolumn{3}{|c|}{ Socioeconomic status } \\
\hline Upper & 421 & 14.17 \\
\hline Upper middle & 495 & 19.43 \\
\hline Lower middle & 621 & 22.80 \\
\hline Upper lower & 530 & 20.80 \\
\hline Lower & 481 & 18.88 \\
\hline \multicolumn{3}{|l|}{ Occupation } \\
\hline Housewife & 1437 & 56.40 \\
\hline Semiskilled worker & 385 & 15.11 \\
\hline Skilled worker & 495 & 19.43 \\
\hline Profession & 231 & 9.07 \\
\hline \multicolumn{3}{|l|}{ Parity } \\
\hline Nulliparous & 1347 & 52.86 \\
\hline Multiparous & 1201 & 47.13 \\
\hline \multicolumn{3}{|c|}{ Gestational age (weeks) } \\
\hline$<34$ weeks & 68 & 2.67 \\
\hline 34-36.6 weeks & 363 & 14.25 \\
\hline 37-39.6 weeks & 1684 & 66.09 \\
\hline 40-41.6 weeks & 431 & 16.92 \\
\hline$\geq 42$ weeks & 2 & 0.08 \\
\hline
\end{tabular}

Table 2: Place from where women referred.

\begin{tabular}{|lll|}
\hline Referred from & $\begin{array}{l}\text { Number of } \\
\text { patients }\end{array}$ & Percentage \\
\hline District hospital & 443 & 43.21 \\
\hline PHC & 266 & 28.32 \\
\hline Private hospital & 219 & 22.44 \\
\hline Medical college (other) & 58 & 6.03 \\
\hline Total & $\mathbf{9 8 6}$ & $\mathbf{1 0 0}$ \\
\hline
\end{tabular}

Out of total women who had Caesarean section $61.22 \%$ were done for emergency indication and $38.88 \%$ were done electively. CSR was $70.83 \%$ in referred women and $28.31 \%$ in booked ones (Figure 2). Difference in rate of caesarean section was statistically significant between referred and booked. Out of women who were referred and had CS, maximum referral (43.21\%) was from district hospital, as patients were referred first to civil hospital from other health facilities. $6.03 \%$ referral was from medical colleges (other) of our state and other states as well (Table 2). Out of total women who had CS $38.69 \%$ were referred from other health facilities out of which, $23.45 \%$ visited hospital in routine hours while $76.57 \%$ came in emergency hours. CS and time of admission has statistical significance.

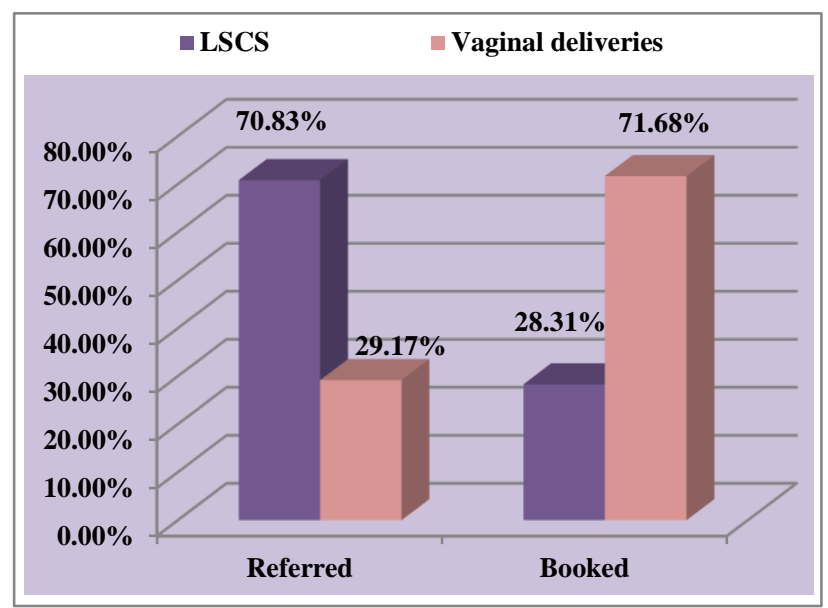

Figure 2: CSR in booked and referred women.

Among all the women who had CS $52.86 \%$ were nulliparous, while $47.13 \%$ were multiparous. CS was maximum $(66.09 \pm 16.92)$ in term women. $16.92 \%$ preterm women underwent CS while only $0.08 \%$ post term had CS (Table 1).

\section{DISCUSSION}

A total of 6908 deliveries were conducted over an audit period of 18 months, out of which the number of parturient delivered by CS were 2548 while 4360 were delivered vaginally. The overall caesarean section rate (CSR) was computed as $36.88 \%$ in our study. This rate is higher than the WHO recommended rates of between 10 and 15 percent. ${ }^{4}$ This is a hospital rate and not population rate, ours being a referral hospital had referrals from nearby hospitals and thereby higher rate. According to the recent NFHS 4, the average rate of C-section in India is 17.2 percent ranging from 5.8 percent in Nagaland to 58.0 percent in Telangana. The difference in C-section delivery from NFHS-1 to NFHS-4 shows that 7 states has CS rate that is more than $30 \%$, eight states has CS rate in between 10 percent and 20 percent and nine states less than 10 percent. $^{5}$

According to the latest data from 1990 to 2014, from 150 countries, currently $18.6 \%$ of all births occur by CS, ranging from $6 \%$ to $27.2 \%$ in the least and most developed regions, respectively. Latin America and the Caribbean region have the highest CS rates (40.5\%), followed by Northern America $(32.3 \%)$, Oceania $(31.1 \%)$, Europe $(25 \%)$, Asia (19.2\%) and Africa $(7.3 \%)^{6}$

In present audit 2548 LSCS were performed, $1560(61.22 \%)$ were emergency as had immediate threat 
to life of women or fetus while $988(38.88 \%)$ CS were elective CS. This is in accordance with another study done by Naeem and Khan et al in tertiary health care hospital in Peshawar in 2011..$^{7}$ A study by Daniel et al in Kerla in 2014 had also reported $46.06 \%$ elective sections and $53.90 \%$ emergency CS. ${ }^{8}$

Frequency of caesarean delivery depends on inherent characteristics of the obstetric population, sociodemographic patterns, referral received by the hospital, departmental policies regarding the management of the cases with dystocia, breech, fetal distress and previous $\mathrm{CS}$, treating physician factor, medico legal aspects and consideration of maternal choice and wishes. Maternal age, parity and fetal weight are the factors over which the obstetricians have little or no control but they have been shown to be crucial determinants of CSR. ${ }^{9}$

Advancing maternal age is an important factor that leads to high CS rates. ${ }^{10}$ This audit found higher number of CS in age group 25-29 years was $1150(45.13 \%)$ followed by in 21-24 years 814 (31.94\%). Many studies conducted by Ecker et al, and Peipert and Bracken in the US, and Kozinszky et al, in Hungary all consistently reported that the increased likelihood of a CS is significantly associated with advancing maternal age, although CS rates differed in these countries. ${ }^{10-12}$ However, in this study age and CS were not associated and CS was seen more among in 25-29 years of age group, probably because of maximum number of this age group women reported to centre during study period.

In India the rural-urban difference between $\mathrm{C}$-section rates is quite conspicuous. The rate of CS is higher in urban areas than their rural counterparts for all the state. However, in this audit about 1479 women who underwent CS were from rural area while 1069 were from urban area. Thus, $58.05 \%$ women who had CS were from rural area, this is because our study centre is a Rural tertiary care centre catering mostly to the rural population. These findings are different from various studies like that done in China by Hong et al in Bangladesh by Simon et al in which caesarean section is more among urban areas. ${ }^{13,14}$ But it has been seen in study that out of total planned LSCS $64.2 \%$ maximum were seen among urban women probably because they were done mainly for women who had an earlier CS. The higher urban rates may be a reflection of combination of factors like higher availability and utilization of maternal health care services. The demand for elective CS from highly educated rich urban women who want to avoid labour pain is increasing is also one of the factors for rising CS rate among urban women.

In present audit it was noted that Caesarean section was at higher side among lower middle class $(22.80 \%)$ followed by in upper lower $(20.80 \%)$ which was in contrast with ,study done by Kaur J and Singh S which found that mothers belonging to high socioeconomic status $(18.46 \%)$ had high incidence of CS which has been proved by other researchers. ${ }^{15}$ Audit finding was also in contrast to the study conducted in Canada by Leeb et al, which shows women in Canada's highest income urban neighborhoods are significantly less likely to have CS than those in lowest income areas. ${ }^{16}$ However it was observed that women with planned CS were of upper middle class and were more among urban population. This explains women of higher socioeconomic status had a preference for CS.

The present audit finds that, women who have completed 12 years schooling or graduation are significantly more likely to experience caesarean delivery than those who never attended school. CS rate among illiterate women was $5.85 \%$ while it was highest in women who were educated till higher school $31.87 \%$. Education increases women's decision-making power regarding their own health care and it is believed that many highly educated women prefer elective caesarean. The work of Chacham and Perpetuo and Ghosh and James also depict that higher education is associated with greater incidence of CS. ${ }^{17}$

Obstetric history strongly influences mode of delivery. In current study out of total CS, 46.97\%(1197) were multiparous women while 53.02\%(1351) were nulliparous. A slightly higher number of CS were noted in nulliparous in this audit which has found association with a study done in Brazil by D'Orsi et al, which reports an association between primiparity and $\mathrm{CS}{ }^{18}$ In an another by Bedi $\mathrm{K}$ et al, reported $42.40 \%$ CSR in nulliparous women. ${ }^{19}$

Planned CS i.e were more in multiparous women as previous CS was an indication in majority of cases. Emergency CS were more in nulliparous women. A recent study done by Roberts et al, in Australia has concluded that rising first-birth caesarean rate had drove the overall increase in $\mathrm{CS}^{20}$

Primiparity has also been described as a risk factor for caesarean delivery in several studies, under the hypothesis that obstetricians consider these women less capable of dealing with the difficulties of labor or because they attend a greater number of prenatal appointments, also associated with the phenomenon. Preventing caesareans among primiparas is of vital importance- in the long term, they anticipate the cumulative effects of a previous caesarean with the consequent increased probability of another caesarean among these women.

In present study, it was observed that out of all caesarean section, number of CS was highest $2115(83 \%)$ among term women i.e. with gestational age 37 to 41 weeks and lowest $2(0.07 \%)$ in post-term. In preterm women it was $411(16.93 \%)$. In different category similar findings were noted. This is because though there is policy to extend pregnancy till term but for maternal or foetal indication CS is done before term. Post-term women were less as most of them were referred from outside and other reason 
was the policy of induction adopted in institute to induce women as soon as she reaches 41 weeks.

\section{CONCLUSION}

It was noted that the preference for caesarean section is more in women of 25-29 years, lower middle and upper middle class, rural women, educated up to high school and housewives as these represented the demographic characteristics of the population this centre caters to. This hospital also serves as referral centre from surrounding health facilities increasing the caesarean section rate of the institute.

\section{Funding: No funding sources}

Conflict of interest: None declared

Ethical approval: The study was approved by the Institutional Ethics Committee

\section{REFERENCES}

1. Betrán AP, Gulmezoglu AM, Robson M, Merialdi M, Souza JP, Wojdyla D, et al. WHO global survey on maternal and perinatal health in Latin America: classifying caesarean sections. Repro Health. 2009;6(1):18.

2. Lauer JA, Betrán AP. Decision aids for women with a previous caesarean section. BMJ. 2007;334(7607):1281-2.

3. Arrieta A. Health reform and caesarean sections in the private sector: the experience of Peru. Health Policy. 2011:99.

4. Mukherjee S, Rising cesarean section rate. J Obstet Gynecol India. 2006;56(4):298-300.

5. Radhakrishnan T, Vasanthakumari KP, Babu PK. Increasing trend of caesarean rates in India: Evidence from NFHS-4. JMSCR. 2017;5(8):26167-76.

6. Betrán AP, Ye J, Moller AB, Zhang J, Gülmezoglu $\mathrm{AM}$, Torloni MR. The increasing trend in caesarean section rates: global, regional and national estimates: 1990-2014. PloS one. 2016;11(2):e0148343.

7. Naeem M, Khan MZ, Abbas SH, Khan A, Adil M, Khan MU. Rate and indications of elective and emergency caesarean section; a study in a tertiary care hospital of Peshawar. J Ayub Med College Abbottabad. 2015;27(1):151-4.

8. Daniel S, Viswanathan M, Simi BN, Nazeema A. Comparison of fetal outcomes of emergency and elective caesarean sections in a teaching hospital in Kerala. Acad Med J India. 2014;2(1):32-6.

9. Parrish KM, Holt VL, Easterling TR, Connell FA, LoGerfo JP. Effect of changes in maternal age, parity, and birth weight distribution on primary cesarean delivery rates. JAMA. 1994;271(6):443-7.
10. Peipert JF, Bracken MB. Maternal age: an independent risk factor for cesarean delivery. Obstet Gynecol. 1993;81(2):200-5.

11. Ecker JL, Chen KT, Cohen AP, Riley LE, Lieberman ES. Increased risk of cesarean delivery with advancing maternal age: indications and associated factors in nulliparous women. Am J Obstet Gynecol. 2001;185(4):883-7.

12. Kozinszky Z, Orvos H, Zoboki T, Katona M, Wayda $\mathrm{K}$, Pál A, et al. Risk factors for cesarean section of primiparous women aged over 35 years. Acta Obstet et Gynecol Scandinavica. 2002;81(4):313-6.

13. Hong $X$. Factors related to the high cesarean section rate and their effects on the" price transparency policy" in Beijing, China. The Tohoku J Exp Med. 2007;212(3):283-98.

14. Collin SM, Anwar I, Ronsmans C. A decade of inequality in maternity care: antenatal care, professional attendance at delivery, and caesarean section in Bangladesh (1991-2004). Int J Equity Health. 2007;6(1):9.

15. Kaur J, Singh S, Kaur K. Current trend of caesarean sections and vaginal births. Adv Applied Sci Res. 2013;4(4):196-202.

16. Leeb K, Baibergenova A, Wen E, Webster G, Zelmer J. Are there socio-economic differences in caesarean section rates in Canada?. Healthcare Policy. 2005;1(1):48.

17. Gupta A. Levels and socio-economic determinants of caesarean section delivery in Northeast and EAG States of India. In Selected Papers of Bhopal Seminar 2015. 2016:91.

18. Barbosa GP, Giffin K, Angulo-Tuesta A, Gama AD, Chor D, D'Orsi E, Reis AC. Parto cesáreo: quem o deseja? Em quais circunstâncias?. Cadernos de Saúde Pública. 2003;19:1611-20.

19. Kambo I, Bedi N, Dhillon BS, Saxena NC. A critical appraisal of cesarean section rates at teaching hospitals in India. Int $\mathbf{J}$ Gynecol Obstet. 2002;79(2):151-8.

20. Roberts CL, Algert CS, Ford JB, Todd AL, Morris JM. Pathways to a rising caesarean section rate: a population-based cohort study. BMJ open. 2012;2(5):e001725.

Cite this article as: Jain SM, Thool K, Shivkumar PV, Jain MA. Study of sociodemographic factors of women undergoing caesarean section in tertiary care centre of rural area of central India. Int J Reprod Contracept Obstet Gynecol 2019;8:4757-61. 